\title{
Transcriptome analysis reveals the effects of sugar metabolism and auxin and cytokinin signaling pathways on root growth and development of grafted apple
}

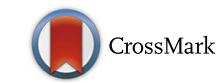

Guofang $\mathrm{Li}^{1 \dagger}$, Juanjuan $\mathrm{Ma}^{1+}$, Ming Tan , Jiangping Mao ${ }^{1}, \mathrm{Na} \mathrm{An}^{1}$, Guangli Sha², Dong Zhang ${ }^{1}$, Caiping Zhao ${ }^{1}$ and Mingyu $\operatorname{Han}^{1 *}$

\begin{abstract}
Background: The root architecture of grafted apple (Malus spp.) is affected by various characteristics of the scions. To provide information on the molecular mechanisms underlying this influence, we examined root transcriptomes of $M$. robusta rootstock grafted with scions of wild-type (WT) apple (M. spectabilis) and a more-branching (MB) mutant at the branching stage.

Results: The growth rate of rootstock grafted MB was repressed significantly, especially the primary root length and diameter, and root weight. Biological function categories of differentially expressed genes were significantly enriched in processes associated with hormone signal transduction and intracellular activity, with processes related to the cell cycle especially down-regulated. Roots of rootstock grafted with MB scions displayed elevated auxin and cytokinin contents and reduced expression of MrPIN1, MrARF, MrAHP, most MrCRE1 genes, and cell growth-related genes MrGH3, MrSAUR and MrTCH4. Although auxin accumulation and transcription of MrPIN3, MrALF1 and MrALF4 tended to induce lateral root formation in MB-grafted rootstock, the number of lateral roots was not significantly changed. Sucrose, fructose and glucose contents were not decreased in MB-grafted roots compared with those bearing WT scions, but glycolysis and tricarboxylic acid cycle metabolic activities were repressed. Root resistance and nitrogen metabolism were reduced in MB-grafted roots as well.
\end{abstract}

Conclusions: Our findings suggest that root growth and development of rootstock are mainly influenced by sugar metabolism and auxin and cytokinin signaling pathways. This study provides a basis that the characteristics of scions are related to root growth and development, resistance and activity of rootstocks.

Keywords: Grafted apple, Root growth and development, Sugar metabolism, Auxin signaling, CKs signaling, Cell cycle

\section{Background}

In terms of nutritional value and economic importance, apple (Malus domestica Borkh.), grape, orange and banana are globally the most predominant fruit crops. Among these four fruit crops, apple is king. Apple production relies heavily on grafting, a technique that combines well-adapted rootstocks with high-quality scions.

\footnotetext{
* Correspondence: hanmy@nwsuaf.edu.cn

${ }^{\dagger}$ Equal contributors

'College of Horticulture, Northwest A \& F University, Yangling, Shaanxi

712100, China

Full list of author information is available at the end of the article
}

Various aspects of scion growth and development, such as plant height, fruiting rate, resistance, physiological and biochemical characteristics and environmental adaptability [1-4], are invariably influenced by the rootstock. Grafting experiments have revealed that plant vascular systems function as transportation corridors for hormones, sugars and RNA molecules [5-7]. Plant vascular systems including xylem and phloem tissues play crucial roles in the transportation of water, minerals and organics substances, and serve as the junction between aboveground and belowground tissues $[5,8]$. Extensive research 
has demonstrated that grafted gain-of-function transcripts can impact tissue development, thereby influencing features such as leaf shape and root architecture [1, 2, 9-11].

The developmental plasticity of roots, which are mainly composed of lateral roots (LRs) and primary roots (PRs), is regulated by hormonal signals and nutrients [12-15]. The relationship of cytokinins (CKs), brassinolide (BR), abscisic acid (ABA), gibberellins (GAs), ethylene and strigolactones are related to auxin biosynthesis, transport, distribution and/or signalling is relatively clear [16-19]. As nutrient components, the main targets of sugar signals are auxin, $A B A$ and $C K$ signalling processes $[20,21]$.

Auxin transport and signalling play essential roles in PR growth and LR formation [22-24]. CKs, which are antagonistic to auxin, repress PR growth and LR initiation by suppressing cell differentiation [25-27]. This antagonism between auxin and CKs in PRs was mediated by SHORT HYPOCOTYL 2 (SHY2) [28, 29]. Arabidopsis response regulator 1 (ARR1), which activates CK signaling, binds directly to the $S H Y 2$ promoter region. In response to auxin, SHY2 degradation is induced to enable auxin transport and distribution. During LR formation, signaling components including histidine kinases (AHKs) and ARRs are also involved in the inhibitory effect of CK [30, 31], which research has shown is unaffected by the addition of auxin [32].

In roots, cell cycle and differentiation-related genes, such as CYCA2;1, CYCA2;4, CYCB1;1, CYCD1;1, CYCD3;2 and CDKB2;1, are activated by auxin [33-35]. Several root development-related genes identified from studies of root phenotypic mutants, are responsible for meristematic activity [36]. For instance, SHORT ROOT (SHR) is specifically expressed in root column vascular tissues to regulate root longitudinal growth $[37,38]$. Even when treated with exogenous auxin, the aberrant lateral root formation-4 (alf4) only has normal PRs but no LRs [39].

In grafted apple seedlings, rootstock root architecture, resistance and root regeneration are affected by the scion [40,41]. The molecular mechanisms underlying these effects are poorly understood. With the availability of the apple complete genome sequence and the advance of next-generation high-throughput RNA sequencing (RNA-seq) technology, genome-wide transcriptome analysis can be applied to study gene expression patterns in different tissues under various conditions during apple root growth and development.

After grafting scions with consistent genetic backgrounds onto identical rootstock materials, we used RNAseq of roots to analyze gene expression patterns of development-related biological processes. A combined analysis of plant growth dynamics and hormone and sugar contents in roots indicated that scion characteristics can influence rootstock phenotypes, which were mainly regulated by auxin and CK signaling pathways. Root activity and resistance were also influenced. These results may be helpful for further understanding of the mechanisms that cause grafting and internal conditions to influence root growth and development.

\section{Results}

\section{Phenotypic changes in grafted seedlings}

To quantify the effect of scions on rootstock phenotype, we grafted seedlings of wild type (WT) M. spectabilis 'Bly114' and its more-branching mutant (MB) onto identical M. robusta rootstocks. Scions of young plants displayed similar phenotypes, with obvious differences appearing at the branching stage (60 days after scion bud germination) (Fig. 1b and e). PR length and diameter and root fresh weight were reduced in MB-bearing rootstock compared with WT-grafted material, whereas the number of LRs was slightly but not significantly higher (Fig. 1c, d and f). To assess the relative proportion of LR growth to total root growth, we used the ratio of LR number to total root weight. As shown in Fig. 1g, this ratio was higher in MB-bearing rootstock. This ratio progressively decreased in both MB- and WT-bearing rootstocks as the growth period was extended. These results indicate that root growth, particularly the primary root, is the main process.

\section{Quantitative analysis of sugars, photosynthetic parameters and hormones}

To evaluate nutrient levels, we measured levels of soluble sugars, including sucrose, glucose, fructose and sorbitol, in roots, stems and leaves at early growth and branching stages ( 25 and 60 days after scion bud germination, respectively) (Fig. 2). At the early growth stage (Fig. 2a-c), the only significant difference was that sorbitol levels were lower in stems of MB than in WT scions (Fig. 2b). At the branching stage, levels of all soluble sugars in the two scions were highest in MB leaves and lowest in MB stems (Fig. 2d and e), which indicates that sugars were concentrated in MB leaves with lower output. Sorbitol content was relatively lower in roots of MB-bearing rootstock while fructose content was slightly higher (Fig. 2f). Compared with WT scions, total soluble sugar content of stems and roots was lower in MB scions and that of leaves was higher.

Moreover, net photosynthetic efficiency $(P n)$ was higher in WT than MB leaves and was not balanced by the lower stomatal conductance $(G s)$ needed for equal intercellular $\mathrm{CO}_{2}$ concentration $(\mathrm{C} i$ ) (Additional file 1).

Zeatin riboside (ZR), ABA and indole acetic acid (IAA) contents were significantly higher in roots of MBbearing rootstock, while GAs contents were unchanged (Fig. 3c). The ABA content of shoot tips, stems and roots of grafted $\mathrm{MB}$ was obviously higher than that of grafted WT, whereas IAA content was higher in stems 

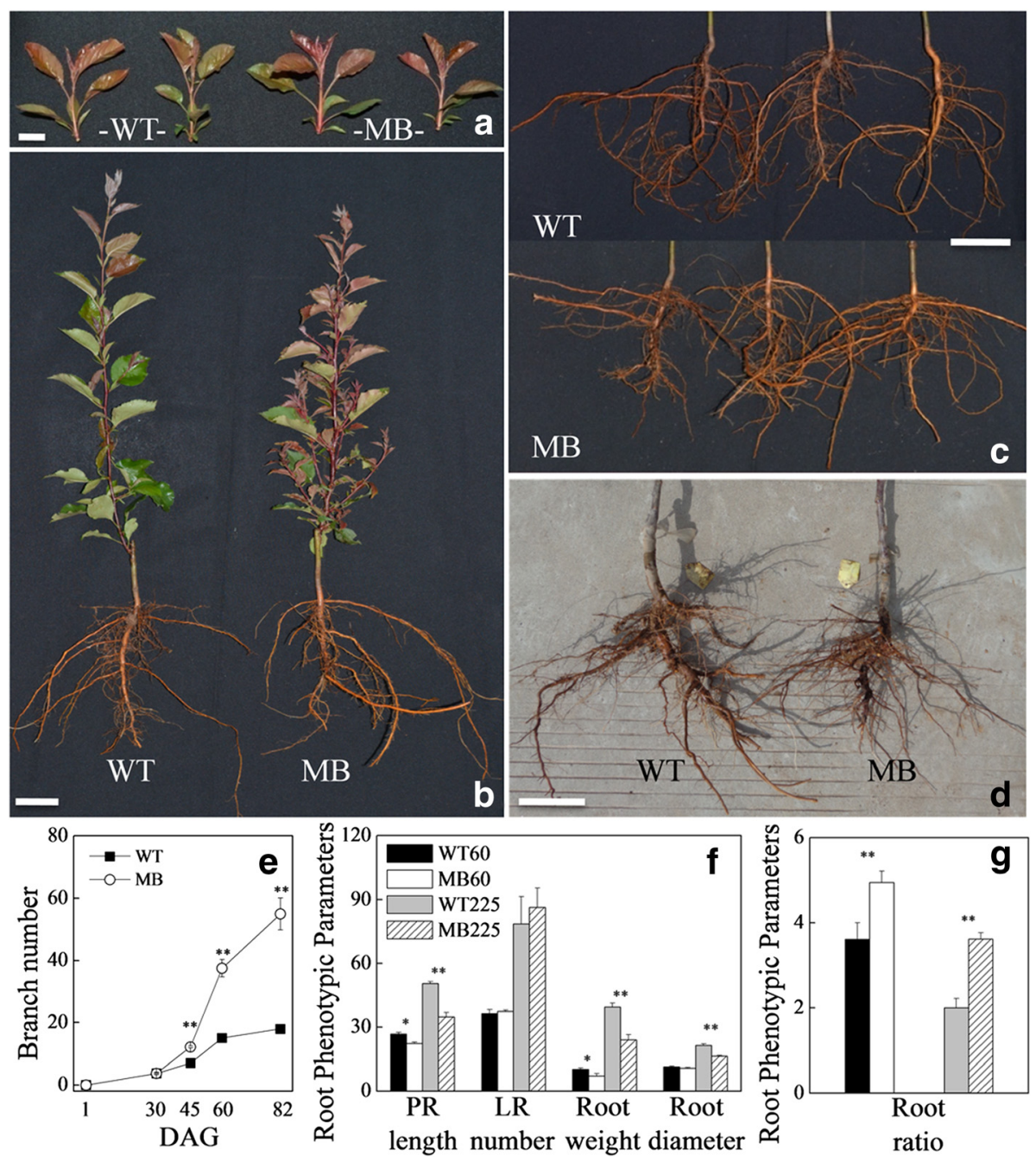

Fig. 1 Phenotypic changes in wild-type (WT) and more-branching (MB) grafted apple (M. spectabilis) scions and M. robusta rootstock. a-b Branching phenotypes of WT and MB grafted scions at different growth stages (a, 25 days after scion bud germination [DAG]; b, 60 DAG); c-d Root phenotypes at the branching stage ( 60 and $225 \mathrm{DAG}$ ). e- $\mathbf{g}$ Comparison of branching number, root phenotypic parameters and root ratio. Data are means \pm SE $(n=10)$. Root ratio was assessed by the relative proportion of $L R$ number to total root weight. Significant differences $\left({ }^{*} P<0.05\right.$ and $\left.{ }^{* *} P<0.01\right)$ are based on Student's t-test. Scale bars $=2.0 \mathrm{~cm}(\mathbf{a}), 5.0 \mathrm{~cm}(\mathbf{b}), 10.0 \mathrm{~cm}(\mathbf{c})$ and $10.0 \mathrm{~cm}(\mathbf{d})$

and shoot tips, but not roots, of grafted WT (Fig. 3a-c). These data demonstrate that higher IAA and ZR in roots of MB-bearing rootstock should be closely related to its root anatomy (Fig. 1d).

\section{Tissue sampling, RNA-seq and analysis of differentially expressed genes}

To gain global insights into the molecular mechanisms responsible for the different phenotypes (Fig. 1c-e), root apex samples without LRs [42] were collected from WT and $\mathrm{MB}$ for transcriptomic analysis at the branching stage. To ensure data reliability, two samples of each type of seedling were sequenced.

A statistical summary of RNA-seq results is given in Table 1. The genomic mapping rate was greater than
$77.49 \%$, with the gene mapping rate reaching 61.32$61.66 \%$. Identification of differentially expressed genes (DEGs) was based on the criteria of false discovery rate $($ FDR $)<0.001, \mid \log _{2}$ Ratio $\mid \geq 1$, and Reads Per kb per Million mapped reads (RPKM) $\geq 1$ at least in one sample. Venn diagrams of all genes of different expression and DEGs in roots of WT- and MB-bearing rootstock are shown in Fig. 4. Most expressed genes had obviously similar expression levels between the two scion types, suggesting that MB had only a narrow influence on the rootstock. Among DEGs, 2896 were down-regulated and 1543 were up-regulated in root grafted MB.

Gene Ontology (GO) and Kyoto Encyclopedia of Genes and Genomes (KEGG) pathway enrichment analyses were used to respectively identify biological processes and 


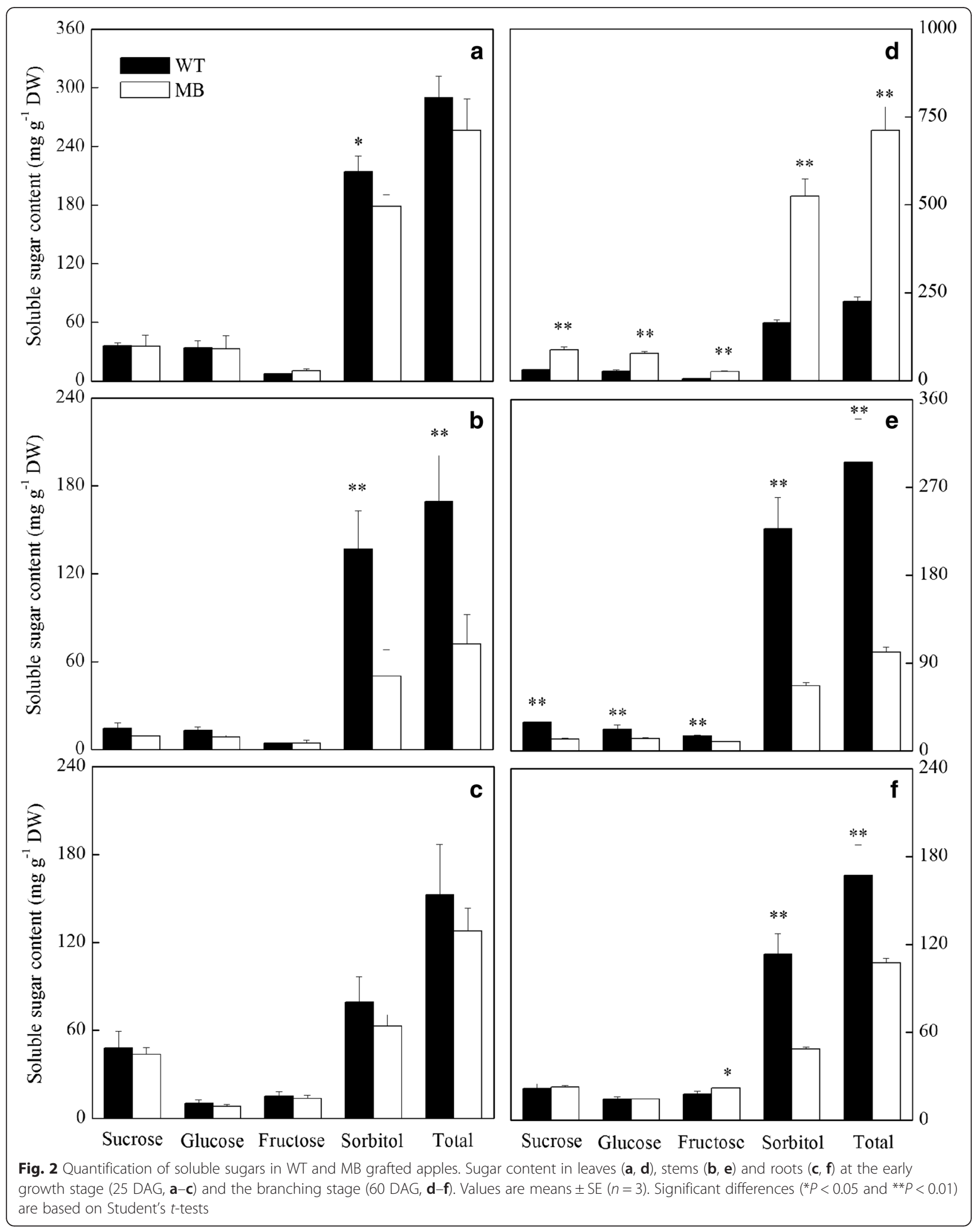




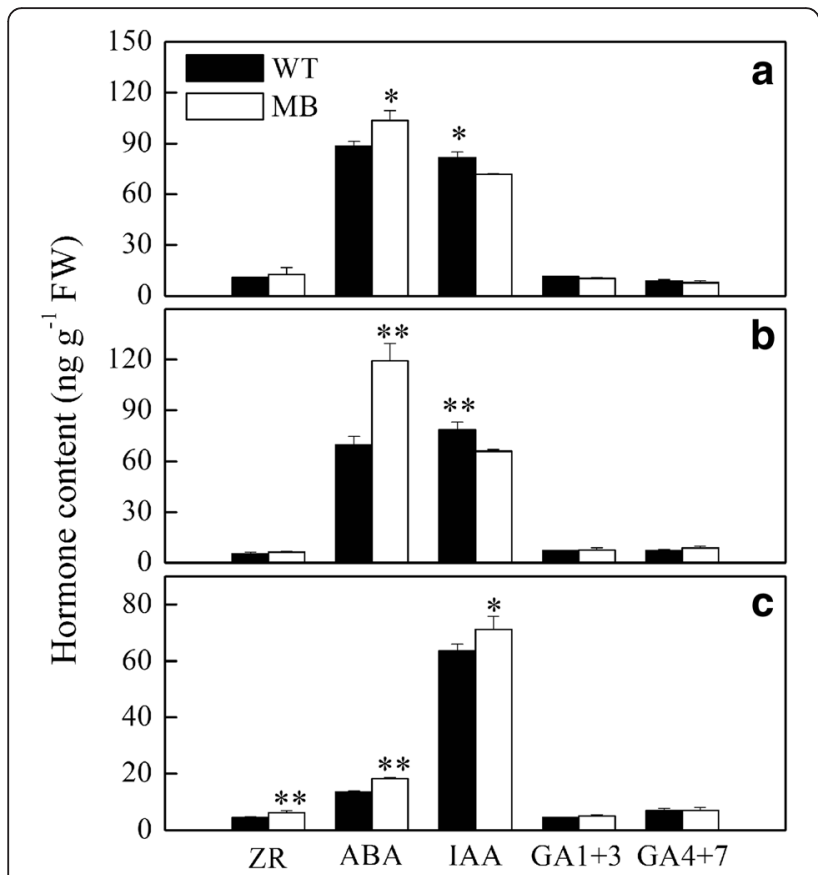

Fig. 3 Quantification of free $Z R, I A A, G A$ s and $A B A$ in $W T$ and $M B$ grafted apple. Hormone content in shoot tips (a), stems (b) and roots $(\mathbf{c})$ at the branching stage (60 DAG). Values are means $\pm \mathrm{SE}$ ( $n=3$, with three technological duplicates). Significant differences $\left({ }^{*} P<0.05\right.$ and $\left.{ }^{* *} P<0.01\right)$ are based on Student's $t$-tests

biological functions enriched in DEGs. Significantly enriched GO biological terms included those in the categories of sugar and phosphate metabolic processes (cluster 1, 7 and 8), response to stimulus and signaling (cluster 2, 3, 5 and 6), cellular activity (cluster 4, 9 and 11) and specific development processes (cluster 10 and 12) (Fig. 5). Furthermore, down-regulated genes were obviously enriched to signal transduction, metabolic process and cellular activity (Additional file 2). The most heavily enriched KEGG pathways were related to hormone signal transduction, specific metabolic processes and biosynthesis (Table 2). To evaluate cellular events, we compiled a list of DEGs with pathway annotations related to hormone signaling pathways and intracellular activity (Table 3). In this list, $61.70 \%$ of genes, primarily falling into pathway categories of hormone signal transduction, RNA polymerase,

Table 1 Summary of RNA sequencing data from roots of M. robusta rootstock grafted with wild-type (WT) and more-branching (MB) M. spectabilis scions

\begin{tabular}{lcccl}
\hline Sample name & Clean reads & $\begin{array}{l}\text { Genome } \\
\text { map rate }\end{array}$ & $\begin{array}{l}\text { Gene } \\
\text { map rate }\end{array}$ & $\begin{array}{l}\text { Expressed } \\
\text { gene }\end{array}$ \\
\hline WT- 1 & 47335946 & $77.86 \%$ & $61.32 \%$ & 38653 \\
WT- 2 & 47142182 & $78.24 \%$ & $61.58 \%$ & 38505 \\
MB- 1 & 47137442 & $77.49 \%$ & $61.66 \%$ & 39377 \\
MB- 2 & 47084672 & $77.70 \%$ & $61.65 \%$ & 39296 \\
\hline
\end{tabular}

brassinosteroid biosynthesis, aminoacyl-tRNA biosynthesis, histidine metabolism and ribosome biogenesis in eukaryotes, were down-regulated.

To validate the reliability of the expression profiles obtained from RNA-Seq, we selected sixteen DEGs for quantitative real-time PCR (qRT-PCR). Notably, the expressed trends between Q-PCR data and RNA-seq data were consistent generally (Fig. 7, Additional files 3, 4 and 5).

\section{Expression of sugar metabolism-related genes}

Sugar content and metabolism were correlated with the status of energy supply status at the branching stage. As shown in the list of sugar metabolism-related genes, most genes especially in the process of glycolysis were significantly repressed in roots of MB-bearing rootstock (Fig. 6 and Additional file 3). Sucrose and glucose contents were undifferentiated, however, while fructose content was a slightly elevated in roots of grafted $\mathrm{MB}$ (Fig. 2).

Sorbitol is the primary photosynthate, translocated carbohydrate and reserve material in woody Rosaceae species such as apple and pear [43]. $\mathrm{NAD}^{+}$-dependent sorbitol dehydrogenase (NAD-SDH; EC 1.1.1.14) catalyzes the transformation of sorbitol to fructose. The four $\mathrm{MrSDHs}$ identified from the DEG analysis were all upregulated (Figs. 6b and 7b). In constrast, isomerase and oxidoreductase genes regulating the transformation of sorbitol to glucose, such as MrMEE31 (MDP0000275261 and MDP0000071829) and MrFEY (MDP0000758881), were down-regulated.

To carry out sugar metabolism via the glycolytic pathway, fructose-6P functions as an integrated element downstream of glucose and fructose. Fructose-6P is synthesized by aldolase superfamily protein (MDP0000309723), mannose-6-phosphate isomerase type I (MDP0000275261) and an $\mathrm{NAD}(\mathrm{P})$-linked oxidoreductase superfamily protein (MDP0000201632), all of which were significantly repressed in MB-bearing rootstock roots (Fig. 6b). Aconitase 2 (MDP0000180604), isocitrate dehydrogenase (MDP0000 163886) and ATP-citrate lyase A-3 (MDP0000931334) in tricarboxylic acid (TCA) cycle were down-regulated. Phosphoenolpyruvate carboxykinase 1 (EC 4.1.1.49), which catalyzes the synthesis of phosphoenolpyruvate that mediates glycolysis and gluconeogenesis, was also down-regulated (Figs. 6c and 7b).

\section{Expression of hormone signaling-related genes}

Selected hormone signaling-related genes encoding receptors and response factors, identified from KEGG pathway analysis, were shown (Fig. 7a, c-d, Additional file 4). The most obvious physiological effect of auxin is the promotion of organ and whole plant growth, which requires auxin transportation and signal transduction. 


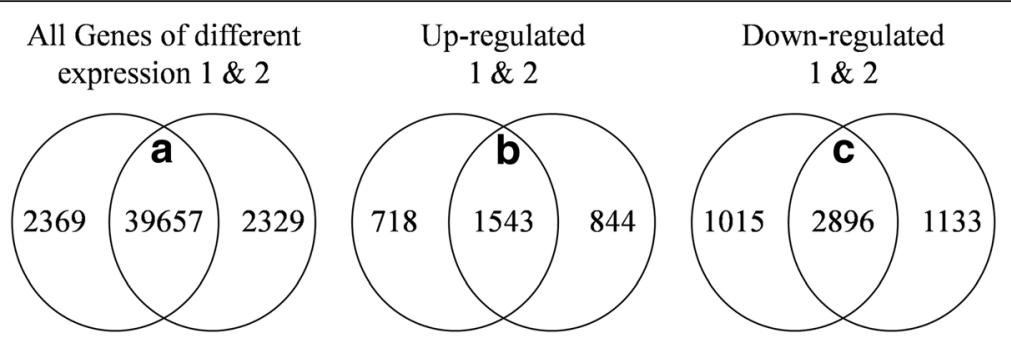

Fig. 4 Venn diagrams of all genes of different expression and DEGs between roots of grafted WT and MB apple. a The intersection of Venn diagram indicating that all genes of different expression were identified both in two difference analysis pairs (WT-1-VS-MB-1 and WT-2-VS-MB-2). b-c The intersection of Venn diagram indicating that genes were up- and down-regulated both in two difference analysis pairs

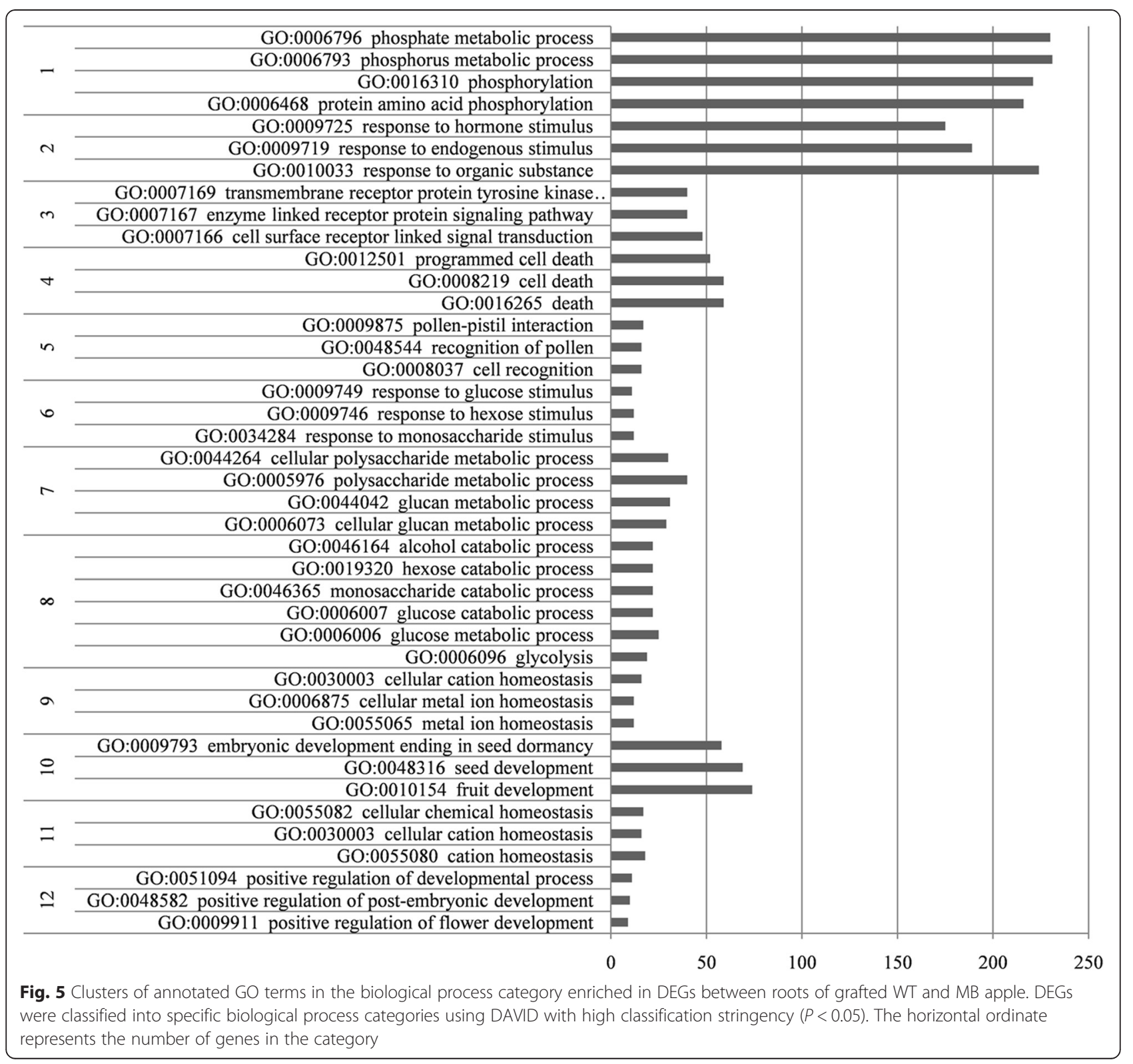


Table 2 KEGG pathway enrichment analysis of DEGs $(P<0.05)$

\begin{tabular}{|c|c|c|c|c|}
\hline Pathway & $\begin{array}{l}\text { DEGs with pathway } \\
\text { annotation (2774) (1612) }\end{array}$ & $\begin{array}{l}\text { All genes with pathway } \\
\text { annotation (35611) (35611) }\end{array}$ & Q-value & Pathway ID \\
\hline Plant-pathogen interaction & $653(16.68 \%)$ & $3658(10.27 \%)$ & $2.653051 e-37$ & ko04626 \\
\hline Plant hormone signal transduction & $312(7.97 \%)$ & 2107 (5.92\%) & $1.177574 \mathrm{e}-06$ & ko04075 \\
\hline Flavonoid biosynthesis & $108(2.76 \%)$ & $666(1.87 \%)$ & $1.030723 \mathrm{e}-03$ & ko00941 \\
\hline Zeatin biosynthesis & $54(1.38 \%)$ & $310(0.87 \%)$ & $1.385799 \mathrm{e}-02$ & ko00908 \\
\hline Flavone and flavonol biosynthesis & $51(1.3 \%)$ & $306(0.86 \%)$ & 4.068123e-02 & ko00944 \\
\hline Biosynthesis of secondary metabolites & $621(15.86 \%)$ & $5111(14.35 \%)$ & 4.068123e-02 & ko01110 \\
\hline$A B C$ transporters & $57(1.46 \%)$ & $358(1.01 \%)$ & 4.068123e-02 & ko02010 \\
\hline Galactose metabolism & 39 (1 \%) & $226(0.63 \%)$ & 4.068123e-02 & ko00052 \\
\hline Carotenoid biosynthesis & $54(1.38 \%)$ & $337(0.95 \%)$ & 4.068123e-02 & ko00906 \\
\hline Benzoxazinoid biosynthesis & $33(0.84 \%)$ & $184(0.52 \%)$ & $4.068123 \mathrm{e}-02$ & ko00402 \\
\hline Purine metabolism & $168(4.29 \%)$ & $1254(3.52 \%)$ & 4.496028e-02 & ko00230 \\
\hline
\end{tabular}

Table 3 KEGG pathways related to hormone signaling and intracellular activity

\begin{tabular}{|c|c|c|c|c|}
\hline Pathway & Pathway ID & Gene number & Up & Down \\
\hline Plant hormone signal transduction & ko04075 & 312 & 92 & 220 \\
\hline RNA polymerase & ko03020 & 135 & 30 & 105 \\
\hline ABC transporters & ko02010 & 57 & 13 & 44 \\
\hline Zeatin biosynthesis & ko00908 & 54 & 13 & 41 \\
\hline Brassinosteroid biosynthesis & ko00905 & 18 & 1 & 17 \\
\hline Histidine metabolism & ko00340 & 10 & 1 & 9 \\
\hline Endocytosis & ko04144 & 42 & 29 & 13 \\
\hline Protein processing in endoplasmic reticulum & ko04141 & 110 & 69 & 41 \\
\hline SNARE interactions in vesicular transport & ko04130 & 19 & 11 & 8 \\
\hline Nitrogen metabolism & ko00910 & 17 & 4 & 13 \\
\hline DNA replication & ko03030 & 19 & 8 & 11 \\
\hline Homologous recombination & ko03440 & 11 & 3 & 8 \\
\hline Phagosome & ko04145 & 36 & 14 & 22 \\
\hline Mismatch repair & ko03430 & 11 & 4 & 7 \\
\hline Basal transcription factors & ko03022 & 8 & 7 & 1 \\
\hline Base excision repair & ko03410 & 10 & 2 & 8 \\
\hline Aminoacyl-tRNA biosynthesis & ko00970 & 18 & 1 & 17 \\
\hline RNA degradation & ko03018 & 30 & 22 & 8 \\
\hline Ribosome biogenesis in eukaryotes & ko03008 & 29 & 8 & 21 \\
\hline Protein export & ko03060 & 6 & 2 & 4 \\
\hline mRNA surveillance pathway & ko03015 & 35 & 21 & 14 \\
\hline Ubiquitin mediated proteolysis & ko04120 & 49 & 25 & 24 \\
\hline Nucleotide excision repair & ko03420 & 15 & 5 & 10 \\
\hline RNA transport & ko03013 & 62 & 28 & 34 \\
\hline Proteasome & ko03050 & 6 & 3 & 3 \\
\hline Spliceosome & ko03040 & 43 & 29 & 14 \\
\hline Total & & $1162(100 \%)$ & 445 (38.30 \%) & $717(61.70 \%)$ \\
\hline
\end{tabular}


a

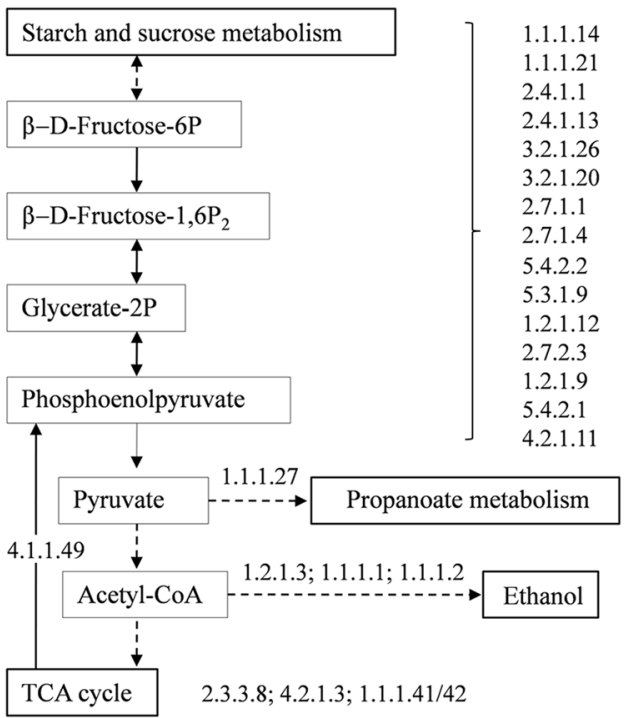

b Starch, sucrose, fructose and sorbitol metabolism $\log _{2}(\mathrm{MB} / \mathrm{WT}) \quad$ Apple genes Names EC

\begin{tabular}{cccc}
1.70 & MDP0000235206 & MrACR4 & 2.4 .1 .1 \\
-2.45 & MDP0000259799 & & 2.4 .1 .1 \\
-1.86 & MDP0000129346 & & 2.4 .1 .1 \\
-1.61 & MDP0000174248 & & 2.4 .1 .1 \\
-1.63 & MDP0000778598 & & 2.4 .1 .1 \\
-1.42 & MDP0000123354 & MrPHS2 & 2.4 .1 .1 \\
-1.05 & MDP0000266061 & MrPHS2 & 2.4 .1 .1 \\
-1.39 & MDP0000177786 & MrSBE2.2 & 2.4 .1 .18 \\
-1.05 & MDP0000214735 & MrSBE2.2 & 2.4 .1 .18 \\
-1.81 & MDP0000585054 & MrSS3 & 2.4 .1 .21 \\
-0.99 & MDP0000191201 & MrSS3 & 2.4 .1 .21 \\
-0.95 & MDP0000276358 & MrSS4 & 2.4 .1 .21 \\
-1.88 & MDP0000256619 & MrADG1 & 2.7 .7 .27 \\
-1.74 & MDP0000293184 & MrAPL3 & 2.7 .7 .27 \\
-1.21 & MDP0000227577 & MrAPL3 & 2.7 .7 .27 \\
-1.14 & MDP0000165351 & MrADG1 & 2.7 .7 .27 \\
-1.39 & MDP0000793357 & & 5.3 .1 .9 \\
-1.33 & MDP0000866748 & MrPGMP & 5.4 .2 .2 \\
1.47 & MDP0000122981 & MrSS1 & 2.4 .1 .21 \\
-1.75 & MDP0000309723 & & 2.7 .1 .4 \\
-1.43 & MDP0000275261 & & 2.7 .1 .4 \\
-1.44 & MDP0000201632 & & 2.7 .1 .4 \\
2.89 & MDP0000849870 & MrHXK2 & 2.7 .1 .1 \\
2.00 & MDP0000643891 & MrHXK2 & 2.7 .1 .1 \\
1.35 & MDP0000776779 & MrPSL5 & 3.2 .1 .20 \\
-1.91 & MDP0000192721 & & 3.2 .1 .20 \\
-1.80 & MDP0000149570 & & 3.2 .1 .26 \\
-2.88 & MDP0000285738 & MrSUS3 & 2.4 .1 .13 \\
-1.11 & MDP0000250070 & MrSUS4 & 2.4 .1 .13 \\
1.32 & MDP0000515106 & MrSDH 6 & 1.1 .1 .14 \\
2.25 & MDP0000759646 & MrSDH & 1.1 .1 .14 \\
1.34 & MDP0000149907 & MrSDH 6 & 1.1 .1 .14 \\
\hline & MDP0000123910 & MrSDH & 1.1 .1 .14 \\
-12 & MDP00000071829 & MrMEE31 & 1.1 .1 .21 \\
-1.13000758881 & MrFEY & 1.1 .1 .21
\end{tabular}

C

Glycolysis / Gluconeogenesis $\log _{2}(\mathrm{MB} / \mathrm{WT}) \quad$ Apple genes

$-1.33 \quad \mathrm{MDP} 0000866748$

-1.39 MDP0000793357

$2.10 \quad$ MDP0000247083

$-4.34 \quad$ MDP0000770587

$-2.50 \quad$ MDP0000123667

$-1.74 \quad$ MDP0000264118

8.69 MDP0000202904

2.62

1.05

MDP0000139833

MDP0000151849

$-2.18 \quad$ MDP0000266003

$-2.51 \quad$ MDP0000481557

$-1.58 \quad$ MDP0000174843

1.04 MDP0000224635

$-8.41 \quad$ MDP0000480605

$-5.46 \quad$ MDP0000292853

$-2.10 \quad$ MDP0000513191

-1.32 MDP0000191423

$-0.97 \quad$ MDP0000302731

$-3.10 \quad$ MDP0000129310

$-1.26 \quad$ MDP0000238942

$-2.21 \quad$ MDP0000293468

$-1.76 \quad$ MDP0000608190

$-1.27 \quad$ MDP0000204764

$2.27 \quad$ MDP0000656568

$-3.84 \quad$ MDP0000472409

$-1.90 \quad$ MDP0000300853

$-2.01 \quad$ MDP0000177897

$-1.33 \quad$ MDP0000173365

$-1.32 \quad$ MDP0000189697

1.45 MDP0000134947

1.45 MDP0000217005

$1.35 \quad$ MDP0000307442

$-2.31 \quad$ MDP0000750456

$-1.31 \quad$ MDP0000287416

$-1.15 \quad$ MDP0000223243

-1.18 MDP0000138249

-1.85 MDP0000214930

$\begin{array}{llll}-1.19 & \text { MDP0000859857 MrALDH2 } & 1.2 .1 .3\end{array}$

-1.63 MDP0000213640 MrALDH2B 1.2.1.3

-1.11 MDP0000790166 MrALDH7B4 1.2.1.3

$8.43 \quad$ MDP0000288647

1.26

$-1.44$

MDP0000494273

MDP0000283455

$-1.15 \quad$ MDP0000680997

$-0.76 \quad$ MDP0000545249

$-1.34 \quad$ MDP0000736683

$-1.36 \quad$ MDP0000133306

$-1.56 \quad$ MDP0000157327

$-1.15 \quad$ MDP0000156898

$-1.14 \quad$ MDP0000071829

$-1.15 \quad$ MDP0000758881

$-1.38 \quad$ MDP0000783824

$\mathrm{MrADH}$

1.1.1.1

1.1.1.1

MrADH1 1.1.1.1

MrADH1 1.1.1.1

1.1.1.2

1.1.1.2

1.1.1.2

1.1.1.2

1.1.1.2

1.1.1.2

1.1.1.2

\section{TCA cycle}

$\begin{array}{llll}-0.86 & \text { MDP0000931334 MrACLA-3 2.3.3.8 }\end{array}$

$\begin{array}{llll}-0.90 & \mathrm{MDP} 0000163886 & \mathrm{MrACO} 2 & 4.2 .1 .3\end{array}$

$\begin{array}{llll}-0.87 & \mathrm{MDP} 0000180604 & \mathrm{MrICDH} & 1.1 .1 .42\end{array}$

$\begin{array}{llll}1.12 & \text { MDP0000147419 } & \text { MrIDH1 } & 1.1 .1 .41\end{array}$

$\begin{array}{llll}1.57 & \text { MDP0000319618 MrIDH1 } & 1.1 .1 .41\end{array}$

1.16 MDP0000131531 MrIDH1 1.1.1.41

-2.95 MDP0000266563 MrCYP87A2 1.1.1.41

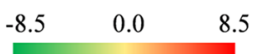

Fig. 6 (See legend on next page.) 
(See figure on previous page.)

Fig. 6 Selected genes related to sugar metabolism from RNA sequencing data. a A schematic diagram of sugar metabolism from starch and sucrose metabolism to TCA cycle. Bounding boxes represent metabolic processes or metabolite, and digit represents regulatory enzyme for specific process. Straight arrow indicates transformational direction of metabolite (solid lines, directly; dotted lines, indirectly). b Selected genes related to starch, sucrose, fructose and sorbitol metabolism. c Selected genes related to glycosis and gluconeogenesis and TCA cycle. Colors indicate the expression values: red indicates up-regulated expression and green indicates down-regulated expression. Data is log base 2 relative to $\mathrm{WT}$ and bases on two duplicates

Auxin transporters identified from the apple genome, MrPIN1 (MDP0000138035), two AUXIN-RESIST-ANT1 (MrAUX1; MDP0000155113, MDP0000s749280) and one NO VEIN (MrNOV; MDP0000806699) were repressed in grafted MB (Fig. 7a, c and Additional file 4), whereas, MrPIN3 (MDP0000497581) and MrAUX1 (MDP00000 80407, MDP0000175425) were activated. Auxin receptor gene TRANSPORT INHIBITOR RESPONSE1 (MrTIR1; MDP0000498419, MDP0000125975), AUXIN F-BOX PROTEIN 5 (MrAFB5; MDP0000809218, MDP000073 4661) and MrSKP2A (MDP0000257953) were activated in MB-bearing rootstock roots, but identified auxin response factors (ARFs) (MDP0000173151, MDP0000123466, MDP 0000179650, MDP0000634433, MDP0000412781, MDP00 00194603) were repressed (Fig. 7a, c and Additional file 4). MrGH3 and small auxin up RNA (MrSAUR), regulating cell enlargement and plant growth downstream of MrARFs, were down-regulated (Fig. 7a and Additional file 4). MrTCH4 and $M r C Y C D 3$, which are downstream of BR signaling and respectively responsible for cell elongation and cell division, were also downregulated (Fig. 7a, e and Additional file 5).

Most CKs receptors (MrCRE1s), which mediate CKmediated repression of LR initiation [32], were significantly repressed in grafted $\mathrm{MB}$ roots (Fig. $7 \mathrm{a}, \mathrm{d}$ and Additional file 4). The genes encoding histidine-containing phosphotransmitters (AHPs), which are positive regulators of CK signaling, were down-regulated. Some type B response regulators (B-ARR) genes were up-regulated while others were simultaneously down-regulated. MrARRs (MDP0000119750, MDP0000250737), which are suppressors of B-ARRs after the acceptance of a phosphate group from AHPs, were significantly up-regulated [44].

Finally, ABA response factors $M r S n R K 2 s$ and $M r A B F s$ were up-regulated in roots of grafted MB (Fig. 7a and Additional file 4). These genes are mainly activated by abiotic stress conditions, such as salt stress, water deprivation and osmotic stress $[45,46]$.

\section{Expression of genes related to root development, the cell cycle and growth}

Several development-related genes operating in root meristem were selected to observe their activities (Fig. 7a, e, f, Additional files 4 and 5). In PRs of grafted MB, Several positive regulatory genes, including $\mathrm{MrSHR}$ (MDPOO 00165587), MrAHK3 (MDP0000181429), MrIAA26 (MDP
0000130583, MDP0000753736, MDP0000164095), POLTERGEIST LIKE 1 (MrPLL1; MDP0000256052) and TORNADO 2 (MrTRN2; MDP0000142574), were repressed significantly, whereas some negative regulatory genes, including WOODEN LEG 1 (MrWOL; MDP0000242242), MrTIR1 (MDP0000125975, MDP0000498419), MrSHY2 (MDP0000324919), RETINOBLASTOMA-RELATED 1 (MrRBR; MDP0000172418) and KIP-RELATED PROTEIN 2 (MrKRP2; MDP0000258414), were significantly upregulated (Fig. 7a, f and Additional file 6). MrALF4 (MDP0000167283), a positive regulator during LR formation, was activated in roots of grafted MB (Fig. 7f). Moreover, LIKE AUXIN RESISTANT 2 (MrLAX2; MDPOOOO 885425) and MrALF1 (MDP0000124971), which negatively regulate the formation of aberrant LRs, were more than 3-fold down-regulated in roots of grafted $\mathrm{MB}$ (Additional file 6). These results were consistent with observed root phenotypes (Fig. 1c and d).

Cells are the basic structural and functional units of organisms. Selected cell cycle-related genes (Fig. 7a and Additional file 5), namely, MrCYCD1 (MDP0000809276, MDP0000231873, MDP0000310564), MrCYCD2 (MDP 0000176105), MrCYCD3 (MDP0000286130, MDP0000 155259), GLUCAN SYNTHASE-LIKE 2 (MrGLS2; MDP 0000286691), K+ TRANSPORTER 1 (MrKT1; MDP0000 216786) and MrKAC2 (MDP0000213592), were significantly repressed in roots of MB-bearing rootstock. Two MrTCH4 genes (MDP0000842877, MDP0000225088), which are positively regulated by BR signaling as well as $M r C Y C D 3$, were down-regulated in roots of grafted MB.

\section{Discussion}

Scion characteristics affect rootstock sugar metabolism

KEGG biological functions pathway analysis indicated that most genes related to hormone signal transduction, cell transcription and translation activity were downregulated (Table 3), thus suggesting that root growth and development rates were repressed both at subcellular and transcriptional levels. However, more intensive changes requires further biochemical verification.

Hetero-grafting experiments have demonstrated that some phloem-mobile transcripts target to root tips and modify root architectures [11]. Given the consistent genetic background between WT and MB, any changes in root phenotypes in the same growth environment can be assumed to stem from differences in scion characteristics 


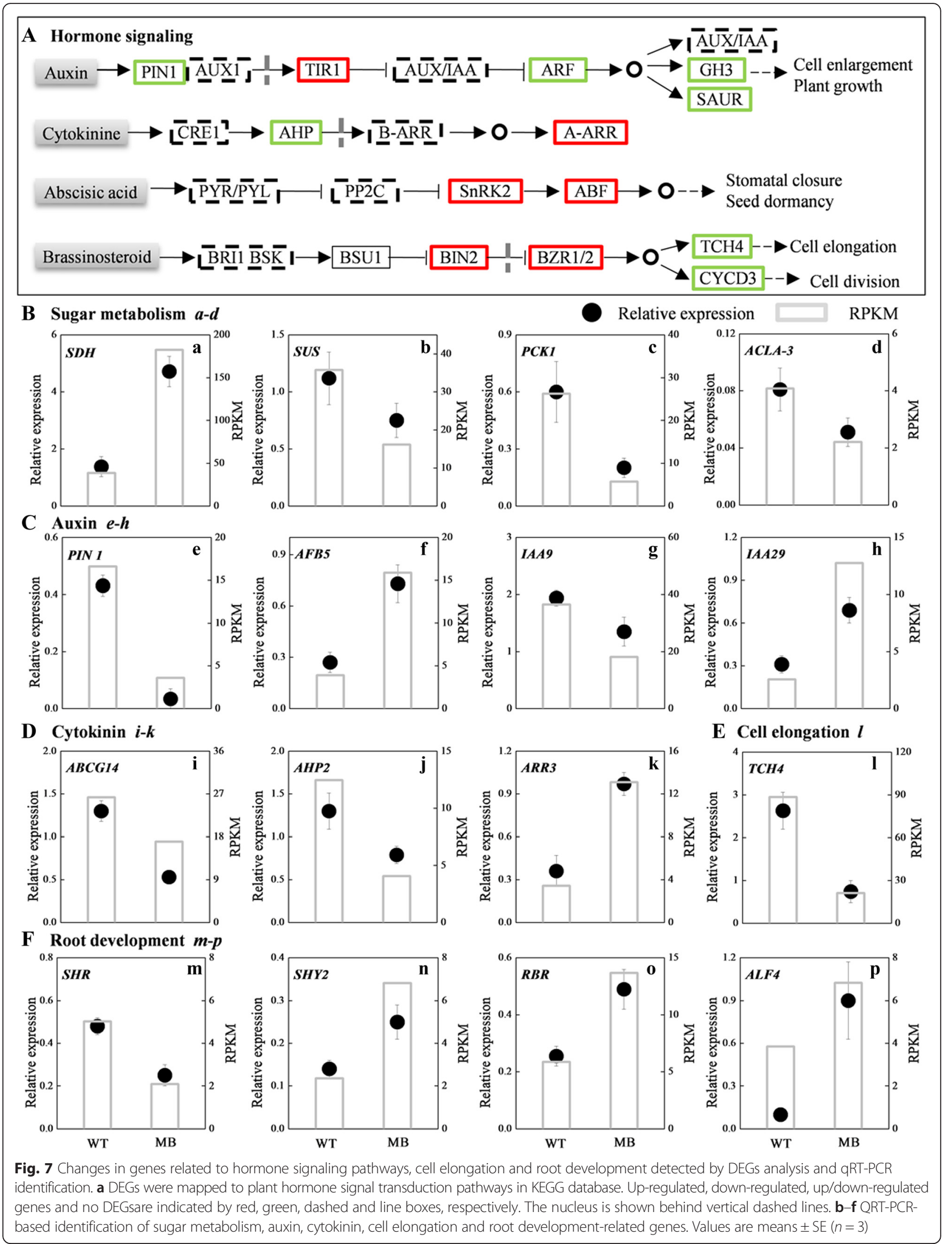


(Fig. 1). Plant growth and development is dependent on hormonal triggers and metabolic factors, such as photosynthetic efficiency and nutrient uptake [15].

Photoassimilates are the only source of sugar in photosynthetic organisms. Although sorbitol content was dramatically decreased in grafted $\mathrm{MB}$ relative to the WT, mainly because of limited photosynthetic ability and transport volume, the contents of sucrose, fructose and glucose in root, required for the glycolytic pathway, were unchanged. The up-regulation of $N A D-S D H s$ is only useful for the sorbitol to fructose transition. Genes related to the TCA cycle as well as most glycolysis genes were also significantly repressed in grafted MB (Fig. 6b-c). Recent studies found that sucrose could also serve as a signal prior to hormonal action in apical dominance and bud outgrowth, and that this was positively concentrationdependent $[30,47]$. These results suggest that the growth and development of grafted MB suffers, at least metabolically, from limitations to glycolysis and the TCA cycle.

\section{Regulation of root development and growth by auxin and CK signaling}

In plants, the auxin pathway, including polar auxin transport and auxin signal transduction processes, is involved in stages of embryonic and postembryonic root development ranging from hypophysis to meristem initiation, emergence and elongation [48-51].

Auxin has tissue-specific and exerts contradictory activities in roots. At high concentrations, auxin inhibits root elongation. Because grafted WT and MB roots had similar auxin contents, however, reduced auxin levels cannot be responsible for the low rate of root growth observed in MB-bearing rootstock (Fig. 3c). Studies have shown that PIN1 and PIN2 localization directs auxin flow in plants; this is particularly true of downward PIN1-dependent flow, which is positively associated with flow volume and growth rate [52-54]. Consistent with those study findings and the low growth rate of grafted $M B$ roots observed in our study, we discovered that the expressions of MrPIN1 and related genes such as $\mathrm{MrSHR}$ were down-regulated in roots grafted MB (Fig. 7a and f). Conversely, however, high auxin and downregulated expression of MrPIN1 can help induce division and differentiation of founder cells [55], events that precede the expression of genes needed for LR formation. Although PIN2, PIN4 and PIN7 can specifically change the distribution of auxin in the root elongation zone [56], the expression of their encoding genes was not detected in this study. Finally, up-regulated MrPIN3 can also increase auxin distribution into pericycle cells to trigger pericycle cell division $[57,58]$.

Following auxin distribution, auxin signal transduction induces downstream gene expression or crosstalk with other hormone signals. In the present study, the presence of an up-regulated auxin receptors, MrTIR1 and MrAFB5, was consistent with the observed higher auxin content and down-regulation of MrAux/IAA transcriptional repressor proteins (Figs. 3, 7a and Additional file 4). As all the genes influenced by auxin are controlled by the activation or inhibition of MrARFs [59]. Therefore, ARFs downregulation may be ultimately responsible for the low rate of root growth observed in grafted $\mathrm{MB}$.

Like auxin, CKs also play a crucial role in regulating meristem activity [60]. According to a previous study, $\mathrm{ZR}$ is the main suppressor of lateral and adventitious root formation [61]. Experimental verification involving CK deficiency and exogenous application indicates that CKs inhibit PR growth and LR initiation within a restricted root meristem region via CRE1/AHK3/B-ARRs signaling [27, 29, 32]. One mode of CK action is the regulation of the expression of genes such as CRE1, SHY2 and PIN1 as well as cell cycle-related genes [30, 32, 62]. In another mode, which does not involve transcripts, CKs specifically promote PIN1 degradation by disturbing its endocytic recycling in vacuoles, and reduce its abundance on the plasma membrane through an unknown mechanism [29]. In MB-bearing rootstock, root phenotypic changes such as PR length and LR number were accordingly consistent with changes of $\mathrm{CK}$ signaling components, such as the up-regulation of MrSHY2 and $M r A-A R R s$ (Figs. 1d, $\mathrm{f}$ and $7 \mathrm{a}$ and Additional file 5). In a study in Arabidopsis, however, exogenous auxin could not rescue the CK-mediated inhibition of LR initiation; in addition, the effect of CKs effect on LR formation was similar between the wild type and auxin mutants harboring in response- and transportation-associated defects [32]. Consequently, CKs and auxin signaling pathways are partially independent during LR initiation; their interaction is more than just a simple antagonism, however, with a balance probably maintained between them in restricted root regions.

\section{Mediation of multiple signaling by root development- related genes}

Specific genes associated with root meristematic activity and differentiation have been identified from root mutants [36]. In Arabidopsis PRs, the balance between cell division and differentiation is coordinated by SHY2, which regulates auxin signaling negatively and CK signaling positively, respectively [28]. SHY2 expression in grafted MB may have been influenced by $\mathrm{CK}$ signaling. As a positive signal of longitudinal growth, SHR expression was specific to roots, dependent on root development and growth [38], and highest in roots of grafted WT. Expressions of $\mathrm{MrGH} 3.9$ and $\mathrm{MrTCH} 4$, responsible for cell elongation or enlargement, were also higher-a response to auxin and BR, respectively (Fig. 7a and Additional file 5). 
Overexpression of $R B R$ rapidly represses stem cell properties, and delays cell division and differentiation $[63,64]$. These changes are similar to the inhibitory effect of KPR2 on CYCD2;1 and cyclin-dependent kinase, which is negatively regulated by auxin $[65,66]$. CYCD2;1 expression is regulated by sucrose, however, which is not responsive to auxin [66]. In our study, MrKPR2 expression was up-regulated in roots of $\mathrm{MB}$-bearing rootstock with higher auxin content (Fig. 3 and Additional file 6), perhaps because this gene is located downstream of MrARFs.

In contrast to the alf4 phenotype, the aberrant lateral root formation-1 (alf1) mutant is characterized by an increased number of LRs [39, 67]. Additionally, ALF4 expression and subcellular locatization of ALF4 are essential to maintain the mitosis of pericycle cells, a process independent of auxin signaling [39]. However, several studies have shown that auxin plays an essential role from LR initiation to LR growth $[32,68]$. Given the expression trends observed for MrALF1 and MrALF4 in our study, grafted $\mathrm{MB}$ should have had a significantly higher number of LRs than grafted WT (Fig. 7f). Consequently, these findings may indicate that the expression of some independent genes for LR development can be repressed by auxin or CK signaling pathways.

\section{Cell division and differentiation during root growth and development}

In roots, active cell division and differentiation primarily occurs in the root meristem zone and may thus regulate the rate of root growth and development [14, 27, 69]. In regard to root growth, the down-regulated expression of cell division- and differentiation- related genes was thus consistent with the root phenotype of grafted MB (Fig. 1d and Additional file 5). The stimulatory effect of auxin on cell division is strongly linked to cell cycle processes. With respect to auxin response, many cell cycle-related genes were in fact up-regulated in roots, whereas cell cycle protein inhibiting factors such as $K R P 1 / 2$, were down-regulated [33, 48, 51].

Apart from auxin, the positive role of BR on root growth and development can also be triggered by stimulating the cell cycle in PR meristem [70]. Moreover, exogenously applied BR can promote the expression of auxin response genes and LR development, with these effects inhibited by N-(1-naphthyl) phthalamic acid (NPA) [16, 71]. When exogenous BR is present, LR development is further activated by the addition of exogenous auxin, which may indicate the existence of a synergistic effect between auxin and BR in root development. In our study, however, brassinazole resistant $1 / 2$ $(B Z R 1 / 2)$ genes, which are positive regulators of the BR signalling pathway, were activated in MB-bearing roots (Fig. 7a and Additional file 4). This result may be evidence that auxin signaling genes function downstream of the BR signaling pathway to regulate root cell division.

Although the cell cycle and cell division are insufficient to activate the formation of LRs or buds [34, 72], the processes of cell division, differentiation and enlargement are required for LR initiation, emergence and elongation, even when restricted to pericycle cells [27, 32]. Furthermore, the overall number of LRs was high in grafted MB (Fig. 1f). This finding suggests that pericycle cell division and differentiation were active in roots of grafted MB. Importantly, these results thus obviously indicate that increased rates of cell division and differentiation in $\mathrm{MB}$ were mainly limited to root growth. As inferred from the correspondence with root morphology in $\mathrm{MB}$ (Fig. 1d), the regulated expression of cell cycle- and growth-related genes may be a direct indicator of root growth.

\section{Scion influences on root resistance and nitrogen metabolism}

ABA plays an important role in plant dormancy and stress resistance $[45,46]$. Although previous studies have variously found that $\mathrm{ABA}$ has negative or positive effects on root development, its effect is mainly related to auxin pathways [18, 73]. Compared with shoot tips and stems, the ABA content of roots was significantly lower in all grafted seedlings (Fig. 3). Moreover, the undifferentiated concentration of soluble sugars in roots, unlike that of leaves, was insufficient to increase osmotic pressure-a factor playing an important role in abiotic stress response [74, 75]. These results suggest that roots are maintained in a relatively stable environment.

Further analysis revealed that the expressions of ABA response factor genes, which induce dormancy and stress responses, were significantly up-regulated in roots of grafted MB (Fig. 7a and Additional file 7). Moreover, expressions of salicylic acid signal-related genes (NPR1 and $P R-1)$ for disease resistance were significantly repressed in roots of $\mathrm{MB}$ (Additional file 7). Concerning root vigor, expressions of nitrogen metabolism relatedgenes for nitrogen uptake and synthesis of amino acids were repressed (Additional file 7). These results indicate that root vigor was suppressed in grafted $\mathrm{MB}$, possibly leading to limitations on root development and growth.

\section{Conclusions}

In this study, root phenotypes of identical rootstock materials were notably influenced by a more branching mutant, compared to wild type. To gain global insights into the molecular mechanisms responsible for different phenotypes based on consistent genetic backgrounds of scions, RNA-seq of roots was performed to analyze gene expression patterns of development-related biological processes. Specific biological functions analysis indicated 
that most genes related to hormone signal transduction, cell transcription and translation activity and sugar metabolism were down-regulated. A combined analysis of plant growth dynamics and sugar and hormone contents in roots indicated that scion characteristics can influence rootstock phenotypes, which were mainly regulated by sugar metabolism and auxin and CK signaling pathways. These results may be helpful for further understanding of the mechanisms that cause grafting and internal conditions to influence root growth and development. Moreover, root activity and resistance are also repressed in roots of grafted MB. These results thus imply that the scion characteristics influencing these processes contribute to root growth and development, resistance and activity of rootstock.

\section{Methods}

\section{Plant material}

Scions from wild-type (WT) M. spectabilis 'Bly114' and a branching mutant (MB) were grafted onto 1-year-old $M$. robusta seedlings. The grafted seedlings were fieldcultivated under natural conditions in Yangling $\left(34^{\circ} 52^{\prime} \mathrm{N}\right.$, $108^{\circ} 7^{\prime}$ E), Shaanxi, China.

For measurements of phytohormone contents and total RNA extraction during the annual growth period when scions presented different branching phenotypes, rootstock roots and scion stems and shoot tips from grafted seedlings were frozen separately in liquid nitrogen and stored at $-80{ }^{\circ} \mathrm{C}$ until further use.

\section{Measurement of root phenotypes and photosynthetic parameters}

Three intact seedlings each of grafted WT and MB were obtained for root and photosynthetic parameter measurements. Roots were scanned using EPSON EXPRESSION $10000 \mathrm{XL}$, and images were analyzed using WinRHIZO system (Regent Instruments, Québec, Canada) [76].

A LI-6400 T portable photosynthesis system (Li-Cor, Lincoln NE, USA) was used for in vivo measurements of photosynthetic parameters, including $\mathrm{Pn}, \mathrm{Gs}$ and $\mathrm{Ci}$ on sunny days between 9:00 and 11:00 a.m. Leaves were illuminated with a 6400-02B light source at a saturating incident photosynthetic photon flux density of $1000 \mu \mathrm{mol}$ $\mathrm{m}^{-2} \mathrm{~s}^{-1}$ from $670-\mathrm{nm}$ red light-emitting diodes with $10 \%$ blue light.

\section{Measurement of sugar and hormone contents}

A total of $0.3 \mathrm{~g}$ (dry weight) of roots, stems, leaves and shoot tips from at least three individual seedlings were used for measurements of soluble sugar and determination of hormone contents [77].

To quantify content of ZR, ABA, IAA and GAs contents, $0.2-\mathrm{g}$ fresh tissues samples were prepared for phytohormone extractions, with hormonal analysis and quantification were performed using the enzyme-linked immunosorbent assay (ELISA) technique [78]. After thorough grinding in liquid nitrogen, the samples were extracted overnight with extracting solution at $4{ }^{\circ} \mathrm{C}$. The extracts were collected after centrifugation, passed through a Sep-Pak $\mathrm{C}_{18}$ cartridge and dried under $\mathrm{N}_{2}$. The residues were dissolved in phosphate buffer. The ELISA for ZR, ABA, IAA and GAs was performed on a 96-well microtitration plate. After adding standard hormone, sample extracts and antibodies, the coated plates were incubated for $40 \mathrm{~min}$ at $37^{\circ} \mathrm{C}$. After rinsing four times, $100 \mu \mathrm{L}$ peroxidase-labeled goat antirabbit immunoglobulin was added to each well and the plate was incubated for $40 \mathrm{~min}$ at $37{ }^{\circ} \mathrm{C}$. Colored substrate (ophenylenediamine) was added to each well, and the reaction was halted by the addition of $3 \mathrm{M} \mathrm{H}_{2} \mathrm{SO}_{4}$. Absorbance at $490 \mathrm{~nm}$ was detected using an ELISA spectrophotometer and used to calculate $\mathrm{ZR}, \mathrm{ABA}$, IAA and GAs contents [79]. Each sample was measured three times, with three replicates.

\section{Total RNA isolation}

Total RNA was isolated from each sample by a modified method [80], and cDNA was synthesized as previously described [81]. RNA integrity was checked on an agarose gel, with RNA concentrations determined using a Nanodrop1000 spectrophotometer (NanoDrop Technologies, Wilmington, DE, USA).

\section{RNA-seq and sequencing}

Total RNA from roots of grafted with WT and MB was subjected to RNA-seq. After total RNA extraction and DNase I treatment, mRNA was isolated from total RNA using magnetic oligo (dT) bends. The mRNA was mixed with fragmentation buffer and cleaved into short fragments for use as templates for cDNA synthesis. Short fragments were purified, resolved with EB buffer for end reparation and single adenine nucleotide addition and connected with adapters. After agarose gel electrophoresis, suitable fragments were selected as templates for polymerase chain reaction (PCR) amplification. During quality control (QC) steps, an Agilent 2100 Bioanalyzer and an ABI StepOnePlus Real-Time PCR system were used for quantification and qualification of sample libraries. Finally, the constructed libraries were sequenced on an Illumina HiSeq 2000 system (BGI, Shenzhen, China).

\section{Transcriptome analysis}

Primary sequencing data, or raw reads, produced on the Illumina system were filtered into clean reads that were aligned to the apple $(M$. domestica) reference genome (http://www.nature.com/ng/journal/v42/n10/full/ng.654. html) using SOAPaligner/SOAP2 [82]. 
Then clean reads was used to calculate the mapped reads on the apple genome and to perform coverage analysis (genome mapping rate) [83]. Gene coverage, the percentage of a gene covered by reads, was calculated as the ratio of the base number in a gene covered by unique mapping reads to the total base number of that gene (gene mapping rate).

\section{Analysis of DEGs}

Unigene expression was calculated using the Reads Per kb per Million mapped reads (RPKM) method [84]. The RPKM method eliminated the influence of different gene lengths and sequencing discrepancies on the gene expression calculations. The calculated gene expression could therefore be used to directly compare differences in gene expression between the samples. In case where more than one transcript was obtained for a gene, the longest transcript was used to calculate expression level and coverage. We identified DEGs between WT and MB transcriptomes according to the following criteria [85]: FDR $<0.001, \mid \log _{2}$ Ratio $\mid \geq 1$, and RPKM $\geq 1$ at least in one sample.

\section{GO and KEGG pathway enrichment analyses}

DEGs were subjected to GO and KEGG pathway enrichment analyses. Compared with the whole genome background, GO enrichment analysis using DAVID (https:// david.ncifcrf.gov/) identified GO terms that were significantly enriched in the list of DEGs and filtered the DEGs corresponding to specific biological functions [86]. KEGG Pathway enrichment analysis in the KEGG Database (http://www.genome.jp/kegg/) was used to identify significantly enriched metabolic or signal transduction pathways in the DEGs [87]. MapMan software was used to display expression profiles at the pathway level [88]. The expression profiles of the metabolic pathways can be viewed by a discrete signal visualized using different colors (blue and red).

\section{Quantification of gene expression}

Specific primers for quantitative real-time PCR (qRTPCR) were designed using Primer 3 software (Additional file 8). To determine the expression of the target genes, PCR amplifications were performed in a $20-\mu \mathrm{L}$ containing SYBR Premix Ex Taq II (Tli RNaseH Plus), with $10 \mu \mathrm{L}$ of $2 \times$ SYBR Premix Ex Taq II (Takara, Beijing, China), and $0.8 \mu \mathrm{L}$ of forward and reverse primers on an iCycler iQ5 (Bio-Rad, USA). The cycling protocol consisted of $95{ }^{\circ} \mathrm{C}$ for $180 \mathrm{~s}$, followed by 39 cycles of $95^{\circ} \mathrm{C}$ for $15 \mathrm{~s}, 58{ }^{\circ} \mathrm{C}$ for $20 \mathrm{~s}$ and $72{ }^{\circ} \mathrm{C}$ for $20 \mathrm{~s}$, followed by 39 cycles to construct a melting curve. The actin gene was used as an internal control for gene expression normalization. Each reaction was performed in triplicate.
The correlation of target genes in expression profiles was measured by qRT-PCR.

\section{Statistical analysis}

Statistical processing of plant phenotype data, sugar and hormone contents and qRT-PCR results was performed in Excel 2007. Differences among means were evaluated by the two-tailed $t$-test with the Statistical Program for Social Science 19 (SPSS, Chicago, IL, USA). Graphs were generated in Excel 2007 and Origin Pro 7.5.

\section{Availability of data and material}

The datasets supporting the conclusions of this article are included within the article and additional files. The dataset of root transcriptomes supporting the conclusions of this article is available in the NCBI Sequence Read Archive repository, the accession is SRR3095691 (http://trace.ncbi.nlm.nih.gov/Traces/sra/sra.cgi?view=run browser), which will be released at 2017-1-6.

\section{Additional files}

Additional file 1: Photosynthetic parameters of WT and MB grafted apple leaves. Comparison of photosynthetic parameters, including net photosynthetic rate $(P n)$, stomatal conductance (Gs) and intercellular $\mathrm{CO}_{2}$ concentration $(C i)$, in WT and MB leaves. Values are means \pm SE $(n=10)$. Significant differences $\left({ }^{*} P<0.05\right.$ and $\left.{ }^{* *} P<0.01\right)$ are based on Student's t-tests. (DOC $111 \mathrm{~kb}$ )

Additional file 2: Clusters of annotated GO terms in the biological process category enriched in Up-regulated (A) and Down-regulated (B) between roots of grafted WT and MB apple. (DOC $2423 \mathrm{~kb}$ )

Additional file 3: Selected genes related to sugar metabolism. (DOC 93 kb)

Additional file 4: Differentially expressed genes related to hormone signaling. (DOC $194 \mathrm{~kb}$ )

Additional file 5: Selected root development-related genes from RNA sequencing data. (DOC $46 \mathrm{~kb}$ )

Additional file 6: Selected differentially expressed genes related to cell division, differentiation and growth. (DOC $39 \mathrm{~kb}$ )

Additional file 7: Selected differentially expressed genes related to salicylic and jasmonic acid signaling and nitrogen metabolism. (DOC $48 \mathrm{~kb}$ )

Additional file 8: Gene-specific primers used for quantitative realtime PCR. (DOC $37 \mathrm{~kb}$ )

Abbreviations

ABA: abscisic acid; CK: cytokinin; LR: lateral root; MB: more branching mutant; PR: primary root; WT: wild type.

Competing interests

The authors declare that they have no competing interests.

Authors' contributions

GFL, JJM, DZ, CPZ and MYH participated in the experimental design and data analysis. GLS provided scions of wild type and a more branching mutant. GFL, MT, JPM and NA performed material sampling, field measurements and the laboratory data measurement. GFL, JJM and MYH participated in the paper writing and manuscript amend. All authors have read and approved the manuscript. 


\section{Acknowledgments}

This work was supported by the National Science and Technology Supporting Project (2013BAD20B03), National Apple Industry Technology System of Agriculture Ministry of China (CARS-28), National Spark Plan Program (2014GA850002), Science and Technology Innovative Engineering Project in Shaanxi province of China (2015NY114), Yangling Subsidiary Center Project of National Apple Improvement Center and Collaborative Innovation of Center Shaanxi Fruit Industry Development. Innovation project of science and technology plan projects of Shaanxi province (2016TZC-N-11-6).

\section{Author details}

${ }^{1}$ College of Horticulture, Northwest A \& F University, Yangling, Shaanxi 712100, China. ${ }^{2}$ Institute of agricultural science, Qingdao, Shandong 266000, China.

Received: 19 October 2015 Accepted: 17 February 2016

Published online: 29 February 2016

\section{References}

1. Kim M, Canio W, Kessler S, Sinha N. Developmental changes due to longdistance movement of a homeobox fusion transcript in tomato. Science. 2001;293(5528):287-9.

2. Haywood V, Yu TS, Huang NC, Lucas WJ. Phloem long-distance trafficking of Gibberellic acid-insensitive RNA regulates leaf development. Plant J. 2005;42(1):49-68.

3. Notaguchi M, Daimon Y, Abe M, Araki T. Adaptation of a seedling micrografting technique to the study of long-distance signaling in flowering of Arabidopsis thaliana. J Plant Res. 2009;122(2):201-14.

4. Xu HY, Zhang WN, Li MF, Harada T, Han ZH, Li TZ. Gibberellic acid insensitive mRNA transport in both directions between stock and scion in Malus. Tree Genet Genomes. 2010;6(6):1013-9.

5. Lough TJ, Lucas WJ. Integrative plant biology: Role of phloem long-distance macromolecular trafficking. Annu Rev Plant Biol. 2006:57:203-32.

6. Spiegelman Z, Golan G, Wolf S. Don't kill the messenger: Long-distance trafficking of mRNA molecules. Plant Sci. 2013;213:1-8.

7. Notaguchi M, Higashiyama T, Suzuki T. Identification of mRNAs that Move Over Long Distances Using an RNA-Seq Analysis of Arabidopsis/Nicotiana benthamiana Heterografts. Plant Cell Physiol. 2015;56(2):311-21.

8. Tabata R, Sumida K, Yoshii T, Ohyama K, Shinohara H, Matsubayashi Y. Perception of root-derived peptides by shoot LRR-RKs mediates systemic N-demand signaling. Science. 2014;346(6207):343-6.

9. Banerjee AK, Chatterjee M, Yu YY, Suh SG, Miller WA, Hannapel DJ. Dynamics of a mobile RNA of potato involved in a long-distance signaling pathway. Plant Cell. 2006;18(12):3443-57.

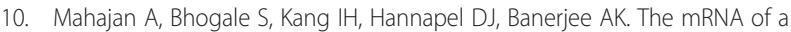
Knotted1-like transcription factor of potato is phloem mobile. Plant Mol Biol. 2012;79(6):595-608.

11. Notaguchi M, Wolf S, Lucas WJ. Phloem-Mobile Aux/IAA Transcripts Target to the Root Tip and Modify Root Architecture. J Integr Plant Biol. 2012;54(10):760-72.

12. lijima M, Barlow PW, Bengough AG. Root cap structure and cell production rates of maize (Zea mays) roots in compacted sand. New Phytol. 2003;160(1):127-34.

13. Giehl RFH, von Wiren N. Root Nutrient Foraging. Plant Physiol. 2014;166(2):509-17.

14. Atkinson JA, Rasmussen A, Traini R, Voss U, Sturrock C, Mooney SJ, Wells DM, Bennett MJ. Branching Out in Roots: Uncovering Form, Function, and Regulation. Plant Physiol. 2014;166(2):538-50.

15. Ljung K, Nemhauser JL, Perata P. New mechanistic links between sugar and hormone signaling networks. Curr Opin Plant Biol. 2015;25:130-7.

16. Bao F, Shen JJ, Brady SR, Muday GK, Asami T, Yang ZB. Brassinosteroids interact with auxin to promote lateral root development in Arabidopsis. Plant Physiol. 2004;134(4):1624-31.

17. Steffens B, Wang JX, Sauter M. Interactions between ethylene, gibberellin and abscisic acid regulate emergence and growth rate of adventitious roots in deepwater rice. Planta. 2006;223(3):604-12.

18. Shkolnik-Inbar D, Bar-Zvi D. ABI4 Mediates Abscisic Acid and Cytokinin Inhibition of Lateral Root Formation by Reducing Polar Auxin Transport in Arabidopsis. Plant Cell. 2010;22(11):3560-73.

19. Guan JC, Koch KE, Suzuki M, Wu S, Latshaw S, Petruff T, Goulet C, Klee HJ, McCarty DR. Diverse roles of strigolactone signaling in maize architecture and the uncoupling of a branching-specific subnetwork. Plant Physiol. 2012;160(3):1303-17.

20. Mishra BS, Singh M, Aggrawal P, Laxmi A. Glucose and Auxin Signaling Interaction in Controlling Arabidopsis thaliana Seedlings Root Growth and Development. Plos One. 2009;4(2):e4502.

21. Sairanen I, Novak O, Pencik A, Ikeda Y, Jones B, Sandberg G, Ljung K. Soluble Carbohydrates Regulate Auxin Biosynthesis via PIF Proteins in Arabidopsis. Plant Cell. 2012;24(12):4907-16.

22. Grieneisen VA, Xu J, Maree AFM, Hogeweg P, Scheres B. Auxin transport is sufficient to generate a maximum and gradient guiding root growth. Nature. 2007:449(7165):1008-13.

23. Dubrovsky JG, Napsucialy-Mendivil S, Duclercq J, Cheng Y, Shishkova S, Ivanchenko MG, Friml J, Murphy AS, Benkova E. Auxin minimum defines a developmental window for lateral root initiation. New Phytol. 2011:191(4):970-83.

24. Ni J, Shen YX, Zhang YY, Liu Y. Histological characterization of the lateral root primordium development in rice. Bot Stud. 2014:55:42

25. Werner T, Motyka V, Laucou V, Smets R, Van Onckelen $H$, Schmulling T. Cytokinin-deficient transgenic Arabidopsis plants show multiple developmental alterations indicating opposite functions of cytokinins in the regulation of shoot and root meristem activity. Plant Cell. 2003;15(11):2532-50.

26. Werner T, Motyka V, Strnad M, Schmulling T. Regulation of plant growth by cytokinin. P Natl Acad Sci USA. 2001;98(18):10487-92.

27. Dello loio R, Linhares FS, Scacchi E, Casamitjana-Martinez E, Heidstra R, Costantino P, Sabatini S. Cytokinins determine Arabidopsis root-meristem size by controlling cell differentiation. Curr Biol. 2007;17(8):678-82.

28. Dello loio R, Nakamura K, Moubayidin L, Perilli S, Taniguchi M, Morita MT, Aoyama T, Costantino P, Sabatini S. A Genetic Framework for the Control of Cell Division and Differentiation in the Root Meristem. Science. 2008;322(5906):1380-4.

29. Marhavy P, Bielach A, Abas L, Abuzeineh A, Duclercq J, Tanaka H, Parezova M, Petrasek J, Friml J, Kleine-Vehn J, et al. Cytokinin Modulates Endocytic Trafficking of PIN1 Auxin Efflux Carrier to Control Plant Organogenesis. Dev Cell. 2011;21(4):796-804

30. Mason MG, Mathews DE, Argyros DA, Maxwell BB, Kieber JJ, Alonso JM Ecker JR, Schaller GE. Multiple type-B response regulators mediate cytokinin signal transduction in Arabidopsis. Plant Cell. 2005;17(11):3007-18.

31. Riefler M, Novak O, Strnad M, Schmulling T. Arabidopsis cytokinin receptor mutants reveal functions in shoot growth, leaf senescence, seed size, germination, root development, and cytokinin metabolism. Plant Cell. 2006;18(1):40-54.

32. Li X, Mo XR, Shou HX, Wu P. Cytokinin-mediated cell cycling arrest of pericycle founder cells in lateral root initiation of Arabidopsis. Plant Cell Physiol. 2006;47(8):1112-23.

33. Himanen K, Boucheron E, Vanneste S, Engler JD, Inze D, Beeckman T. Auxin mediated cell cycle activation during early lateral root initiation. Plant Cell. 2002;14(10):2339-51.

34. Vanneste S, De Rybel B, Beemster GTS, Ljung K, De Smet I, Van Isterdael G, Naudts M, lida R, Gruissem W, Tasaka M, et al. Cell cycle progression in the pericycle is not sufficient for SOLITARY ROOT/IAA14-mediated lateral root initiation in Arabidopsis thaliana. Plant Cell. 2005;17(11):3035-50.

35. Grunewald W, De Smet I, Lewis DR, Lofke C, Jansen L, Goeminne G, Bossche RV, Karimi M, De Rybel B, Vanholme B, et al. Transcription factor WRKY23 assists auxin distribution patterns during Arabidopsis root development through local control on flavonol biosynthesis. P Natl Acad Sci USA. 2012;109(5):1554-9.

36. Takehisa $H$, Sato $Y$, Igarashi M, Abiko T, Antonio BA, Kamatsuki K, Minami H, Namiki $\mathrm{N}$, Inukai $Y$, Nakazono $\mathrm{M}$, et al. Genome-wide transcriptome dissection of the rice root system: implications for developmental and physiological functions. Plant J. 2012;69(1):126-40.

37. Helariutta Y, Fukaki H, Wysocka-Diller J, Nakajima K, Jung J, Sena G, Hauser MT, Benfey PN. The SHORT-ROOT gene controls radial patterning of the Arabidopsis root through radial signaling. Cell. 2000;101(5):555-67.

38. Ueda M, Koshino-Kimura Y, Okada K. Stepwise understanding of root development. Curr Opin Plant Biol. 2005:8(1):71-6.

39. DiDonato RJ, Arbuckle E, Buker S, Sheets J, Tobar J, Totong R, Grisafi P, Fink GR, Celenza JL. Arabidopsis ALF4 encodes a nuclear-localized protein required for lateral root formation. Plant J. 2004;37(3):340-53.

40. Koizumi A, Araki H, Hori H, Inagawa Y. Windthrow resistance of apple trees grafted in an orchard. J Wood Sci. 2008;54(1):10-5. 
41. Webster AD, Vaughan SP, Lucas AS, Spencer JE, Atkinson CJ. Effects of tree age at planting, root manipulation and trickle irrigation on growth and cropping of apple (Malus pumila) cultivar Queen Cox on M.9 rootstock. J Hortic Sci Biotech. 2003;78(5):680-8.

42. Casimiro I, Marchant A, Bhalerao RP, Beeckman T, Dhooge S, Swarup R, Graham N, Inze D, Sandberg G, Casero PJ, et al. Auxin transport promotes Arabidopsis lateral root initiation. Plant Cell. 2001;13(4):843-52.

43. Wang $X L$, Hu ZY, You CX, Kong XZ, Shi XP. Subcellular localization and vacuolar targeting of sorbitol dehydrogenase in apple seed. Plant Sci. 2013;210:36-45.

44. Punwani JA, Hutchison CE, Schaller GE, Kieber JJ. The subcellular distribution of the Arabidopsis histidine phosphotransfer proteins is independent of cytokinin signaling. Plant J. 2010;62(3):473-82.

45. McLoughlin F, Galvan-Ampudia CS, Julkowska MM, Caarls L, van der Does D, Lauriere C, Munnik T, Haring MA, Testerink C. The Snf1-related protein kinases SnRK2.4 and SnRK2.10 are involved in maintenance of root system architecture during salt stress. Plant J. 2012;72(3):436-49.

46. Yoshida T, Fujita Y, Maruyama K, Mogami J, Todaka D, Shinozaki K, Yamaguchi-Shinozaki K. Four Arabidopsis AREB/ABF transcription factors function predominantly in gene expression downstream of SnRK2 kinases in abscisic acid signalling in response to osmotic stress. Plant Cell Environ. 2015;38(1):35-49.

47. Barbier F, Peron T, Lecerf M, Perez-Garcia MD, Barriere Q, Rolcik J, BoutetMercey S, Citerne S, Lemoine R, Porcheron B, et al. Sucrose is an early modulator of the key hormonal mechanisms controlling bud outgrowth in Rosa hybrida. J Exp Bot. 2015;66(9):2569-82

48. Wolters $H$, Jurgens $G$. Survival of the flexible: hormonal growth control and adaptation in plant development. Nat Rev Genet. 2009;10(5):305-17.

49. Coudert Y, Perin C, Courtois B, Khong NG, Gantet P. Genetic control of root development in rice, the model cereal. Trends Plant Sci. 2010;15(4):219-26.

50. Lavenus J, Goh T, Roberts I, Guyomarc'h S, Lucas M, De Smet I, Fukaki H, Beeckman T, Bennett M, Laplaze L. Lateral root development in Arabidopsis: fifty shades of auxin. Trends Plant Sci. 2013;18(8):455-63.

51. Bellini C, Pacurar DI, Perrone I. Adventitious Roots and Lateral Roots: Similarities and Differences. Annu Rev Plant Biol. 2014;65:639-66.

52. Galweiler L, Guan CH, Muller A, Wisman E, Mendgen K, Yephremov A, Palme K. Regulation of polar auxin transport by AtPIN1 in Arabidopsis vascular tissue. Science. 1998;282(5397):2226-30.

53. Wisniewska J, Xu J, Seifertova D, Brewer PB, Ruzicka K, Blilou I, Rouquie D, Benkova E, Scheres B, Friml J. Polar PIN localization directs auxin flow in plants. Science. 2006;312(5775):883-3.

54. Shinohara N, Taylor C, Leyser O. Strigolactone can promote or inhibit shoot branching by triggering rapid depletion of the auxin efflux protein PIN1 from the plasma membrane. PLoS Biol. 2013. doi:10.1371/journal.pbio.1001474.

55. Dubrovsky JG, Sauer M, Napsucialy-Mendivil S, Ivanchenko MG, Friml J, Shishkova S, Celenza J, Benkova E. Auxin acts as a local morphogenetic trigger to specify lateral root founder cells. P Natl Acad Sci USA. 2008;105(25):8790-4

56. Blilou I, Xu J, Wildwater M, Willemsen V, Paponov I, Friml J, Heidstra R, Aida M, Palme K, Scheres B. The PIN auxin efflux facilitator network controls growth and patterning in Arabidopsis roots. Nature. 2005:433(7021):39-44.

57. Marhavy P, Vanstraelen M, De Rybel B, Ding ZJ, Bennett MJ, Beeckman T, Benkova E. Auxin reflux between the endodermis and pericycle promotes lateral root initiation. Embo J. 2013;32(1):149-58.

58. Vermeer JEM, von Wangenheim D, Barberon M, Lee $Y$, Stelzer EHK, Maizel A Geldner N. A Spatial Accommodation by Neighboring Cells Is Required for Organ Initiation in Arabidopsis. Science. 2014;343(6167):178-83.

59. Dharmasiri S, Estelle M. The role of regulated protein degradation in auxin response. Plant Mol Biol. 2002;49(3-4):401-9.

60. Gonzalez-Rizzo S, Crespi M, Frugier F. The Medicago truncatula CRE1 cytokinin receptor regulates lateral root development and early symbiotic interaction with Sinorhizobium meliloti. Plant Cell. 2006:18(10):2680-93.

61. Kuroha T, Sakakibara H. Molecular characterization of Arabidopsis LOG family genes encoding cytokinin activating enzymes. Plant Cell Physiol. 2007:48:S118.

62. Laplaze L, Benkova E, Casimiro I, Maes L, Vanneste S, Swarup R, Weijers D, Calvo V, Parizot B, Herrera-Rodriguez MB, et al. Cytokinins act directly on lateral root founder cells to inhibit root initiation. Plant Cell. 2007;19(12):3889-900.

63. Dinneny JR, Benfey PN. Stem cell research goes underground: The Retinoblastoma-related gene in root development. Cell. 2005;123(7):1180-2.
64. Wildwater M, Campilho A, Perez-Perez JM, Heidstra R, Blilou I, Korthout H, Chatterjee J, Mariconti L, Gruissem W, Scheres B. The RETINOBLASTOMARELATED gene regulates stem cell maintenance in Arabidopsis roots. Cell. 2005;123(7):1337-49.

65. Himanen $K$, Vuylsteke $M$, Vanneste $S$, Vercruysse $S$, Boucheron $E$, Alard $P$, Chriqui D, Van Montagu M, Inze D, Beeckman T. Transcript profiling of early lateral root initiation. P Natl Acad Sci USA. 2004;101(14):5146-51.

66. Sanz L, Dewitte W, Forzani C, Patell F, Nieuwland J, Wen B, Quelhas P, De Jager S, Titmus C, Campilho A, et al. The Arabidopsis D-Type Cyclin CYCD2;1 and the Inhibitor ICK2/KRP2 Modulate Auxin-Induced Lateral Root Formation. Plant Cell. 2011;23(2):641-60.

67. Kong WW, Li Y, Zhang MM, Jin F, Li J. A Novel Arabidopsis MicroRNA Promotes IAA Biosynthesis via the Indole-3-acetaldoxime Pathway by Suppressing SUPERROOT1. Plant Cell Physiol. 2015;56(4):715-26.

68. Vanneste S, Maes L, De Smet I, Himanen K, Naudts M, Inze D, Beeckman T. Auxin regulation of cell cycle and its role during lateral root initiation. Physiol Plantarum. 2005;123(2):139-46.

69. De Smet I, Tetsumura T, De Rybel B, Frey NFD, Laplaze L, Casimiro I, Swarup R, Naudts M, Vanneste S, Audenaert D, et al. Auxin-dependent regulation of lateral root positioning in the basal meristem of Arabidopsis. Development. 2007:134(4):681-90.

70. Gonzalez-Garcia MP, Vilarrasa-Blasi J, Zhiponova M, Divol F, Mora-Garcia S, Russinova E, Cano-Delgado Al. Brassinosteroids control meristem size by promoting cell cycle progression in Arabidopsis roots. Development. 2011;138(5):849-59.

71. Li L, Xu J, Xu ZH, Xue HW. Brassinosteroids stimulate plant tropisms through modulation of polar auxin transport in Brassica and Arabidopsis. Plant Cell. 2005;17(10):2738-53.

72. Muller D, Leyser O. Auxin, cytokinin and the control of shoot branching. Ann Bot. 2011:107(7):1203-12.

73. Chen CW, Yang YW, Lur HS, Tsai YG, Chang MC. A novel function of abscisic acid in the regulation of rice (Oryza sativa L.) root growth and development. Plant Cell Physiol. 2006;47(1):1-13.

74. Folgado R, Sergeant K, Renaut J, Swennen R, Hausman JF, Panis B. Changes in sugar content and proteome of potato in response to cold and dehydration stress and their implications for cryopreservation. J Proteomics. 2014;98:99-111.

75. Du H, Wang Z, Yu W, Huang B. Metabolic Responses of Hybrid Bermudagrass to Short-term and Long-term Drought Stress. J Am Soc Hortic Sci. 2012;137(6):411-20.

76. Wang M-B, Zhang Q. Issues in using the WinRHIZO system to determine physical characteristics of plant fine roots. Acta Ecol Sin. 2009;29(2):136-8

77. Rosa M, Hilal M, González JA, Prado FE. Low-temperature effect on enzyme activities involved in sucrose-starch partitioning in salt-stressed and saltacclimated cotyledons of quinoa (Chenopodium quinoa Willd.) seedlings. Plant Physiol Biochem. 2009:47:300-7.

78. Ivanov Dobrev P, Kamínek M. Fast and efficient separation of cytokinins from auxin and abscisic acid and their purification using mixed-mode solidphase extraction. J Chromatogr A. 2002;950:21-9.

79. Weiler EWJP, Conrad W. Levels of indole-3-acetic acid in intact and decapitated coleoptiles as determined by a specific and highly sensitive solid-phase enzyme immunoassay. Planta. 1981:153:561-71.

80. Xia R, Zhu H, An Y-q, Beers EP, Liu Z. Apple miRNAs and tasiRNAs with novel regulatory networks. Genome Biol. 2012;13:R47.

81. Shalom L, Samuels S, Zur N, Shlizerman L, Zemach H, Weissberg M, Ophir R, Blumwald E, Sadka A. Alternate Bearing in Citrus: Changes in the Expression of Flowering Control Genes and in Global Gene Expression in ON- versus OFF-Crop Trees. PLOS ONE. 2012;7:e46930.

82. Velasco R, Zharkikh A, Affourtit J, Dhingra A, Cestaro A, Kalyanaraman A, Fontana P, Bhatnagar SK, Troggio M, Pruss D, et al. The genome of the domesticated apple (Malus $\times$ domestica Borkh). Nat Genet. 2010;42:833-9.

83. Kim D, Pertea G, Trapnell C, Pimentel H, Kelley R, Salzberg SL. TopHat2: accurate alignment of transcriptomes in the presence of insertions, deletions and gene fusions. Genome Biol. 2013;14:R36.

84. Mortazavi A, Williams BA, Mccue K, Schaeffer L, Wold B. Mapping and quantifying mammalian transcriptomes by RNA-Seq. Nat Methods. 2008;5(7):621-8

85. Benjamini $Y$, Yekutieli $D$. The control of the false discovery rate in multiple testing under dependency. Ann Stat. 2001;29(4):1165-88. 
86. Huang DW, Sherman BT, Lempicki RA. Systematic and integrative analysis of large gene lists using DAVID bioinformatics resources. Nat Protoc. 2009;4(1):44-57.

87. Kanehisa M, Araki M, Goto S, Hattori M, Hirakawa M, Itoh M, Katayama T, Kawashima S, Okuda S, Tokimatsu T, et al. KEGG for linking genomes to life and the environment. Nucleic Acids Res. 2008;36:D480-4.

88. Thimm O, Blasing O, Gibon Y, Nagel A, Meyer S, Kruger P, Selbig J, Muller LA, Rhee SY, Stitt M. MAPMAN: a user-driven tool to display genomics data sets onto diagrams of metabolic pathways and other biological processes. Plant J. 2004;37(6):914-39.

Submit your next manuscript to BioMed Central and we will help you at every step:

- We accept pre-submission inquiries

- Our selector tool helps you to find the most relevant journal

- We provide round the clock customer support

- Convenient online submission

- Thorough peer review

- Inclusion in PubMed and all major indexing services

- Maximum visibility for your research

Submit your manuscript at www.biomedcentral.com/submit
Biomed Central 